\title{
Exostosis a Dangerous Location: A Case Report and Literature Review
}

\author{
R. Ait Mouha, K. Ahed, M. Fahsi, N. Omari, R. Haddoun \\ Traumatilogy and Orthopedics, Traumatology and Orthopedics University Hospital, Casablanca, Morocco \\ Email: aitmouharachid@gmail.com
}

How to cite this paper: Mouha, R.A., Ahed, K., Fahsi, M., Omari, N. and Haddoun, R. (2016) Exostosis a Dangerous Location: A Case Report and Literature Review. Open Access Library Journal, 3: e2964.

http://dx.doi.org/10.4236/oalib.1102964

Received: August 9, 2016

Accepted: September 3, 2016

Published: September 6, 2016

Copyright $\odot 2016$ by authors and Open Access Library Inc.

This work is licensed under the Creative Commons Attribution International

License (CC BY 4.0).

http://creativecommons.org/licenses/by/4.0/

\section{Open Access}

\begin{abstract}
The osteogenic exostosis or osteochondroma usually reveals a tumor siting preferably in the knee area. Vascular complications exostoses are known and exceptional even if the frequency of these tumors is important, and we related a case report about a young man of 23 years old who suffers from a mass filling the popliteal area of the left knee, projecting on the popliteal pedicle. We proceed to the excision of the entire lesion. The arterial pseudoaneurysm is the most common vascular complication of exostosis especially in his popliteal location. MRI angiography is necessary, to mentioned osteochondroma aspect, the rule is: any painful exostosis must be removed because the risks of degeneration are real but rare.
\end{abstract}

\section{Subject Areas}

Orthopedics

\section{Keywords}

Exostosis, Osteochondroma, Pseudoaneuvrysm, Complication

\section{Introduction}

The osteogenic exostosis or osteochondroma is extended peripheral tumor on the surface of the bone often budding. The lesion is usually reveals a tumor siting preferably in the knee area. It is generally unique [1]. His budding appearance on the bone allows the diagnosis without need a surgical biopsy like reported by Gouin and Wirganowicz [1] [2]. Its treatment is radical (total resection) as soon as it starts to hurt. Vascular complications exostoses are known and exceptional even if the frequency of these tumors is important as discussed elsewhere [3]-[6]. 


\section{Case Report}

A young man of 23 years old was sent to us for a mass filling the popliteal area of the left knee, the mass changes since childhood but progressively increased in two last years with a slight pain in the march accompanied by paresthesia, and limiting mobility.

The examination revealed a large mass of $10 \mathrm{~cm}$ diameter, filling more than twothirds of lower popliteal area (Figure 1), unpainful, fixed to deep plant, bone consistency, without skin disorder, mobilized during flexion probably related to the posterior side of the tibial metaphysic, projecting on the popliteal pedicle, dorsalis pedis lice were collected symmetrically on both sides without other nervous disorders.

Radiography of the knee shows an image of a pedicle bone tumor, with a broad base to the posterior aspect of the proximal tibial metaphyseal, Although limited, lobed with images of remodeling and sclerosis (Figure 2), MRI angiography aspect mentioned osteochondroma, without achieving the soft part and driving back significantly the popliteal neurovascular bundle posteriorly with a significant risk of intimal injury (Figure 3).

We proceed to the excision of the entire lesion using a Triquet surgical exposure (Figure 4), sparing the neurovascular bundle that has a intimate relationship wrapping the superficial face of the mass (Figure 5, Figure 6). The immediate postoperative course was simple and 6 months after all clinical symptoms had disappeared.

\section{Discussion}

Exostoses are osteochondral growths, they occur most often on the surface of the metaphyseal region of long bones as reported elsewhere [1] [2]. The exostoses can also cause rare vascular complications often arterial (pseudoaneurysm, arterial compression or rupture, arterial thrombosis) and venous more rarely [6] [7]. The arterial pseudoaneurysm is the most common vascular complication especially in his popliteal location

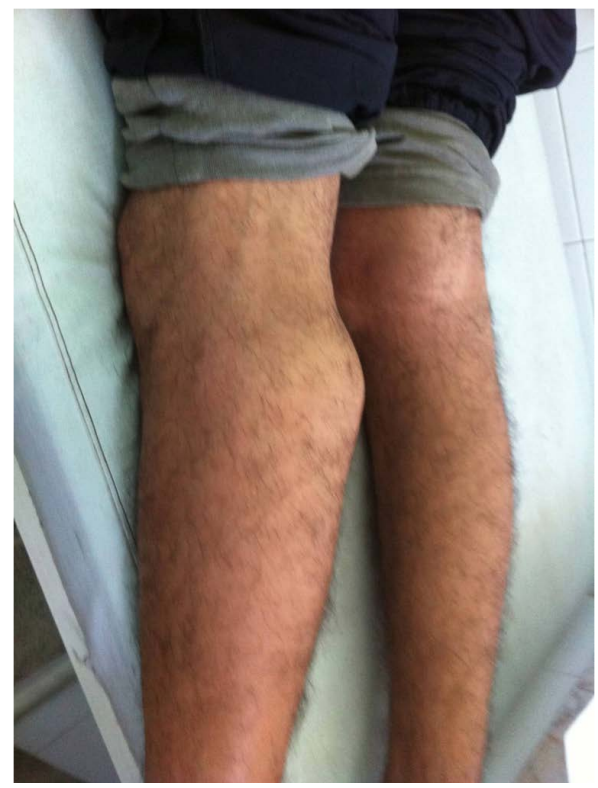

Figure 1. A mass filling the popliteal area of the left knee. 


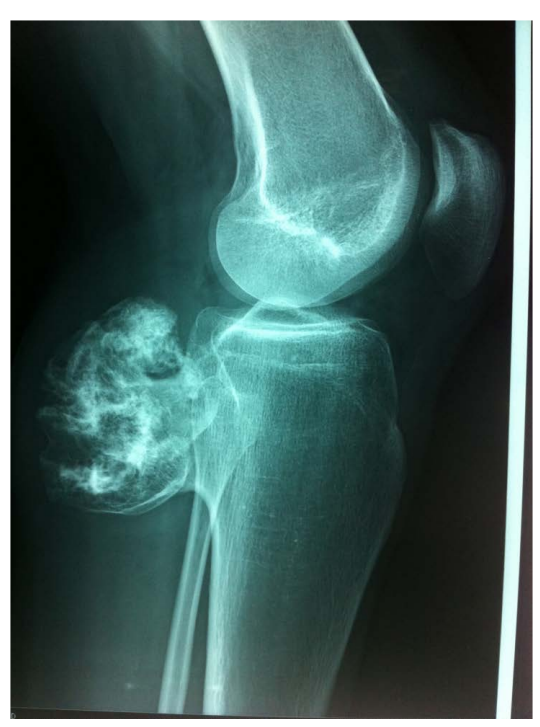

Figure 2. Radiography of the left knee shows an a pedicle bone tumor based to the posterior aspect of the proximal tibial metaphyseal, Although limited, lobed with images of remodeling and sclerosis.

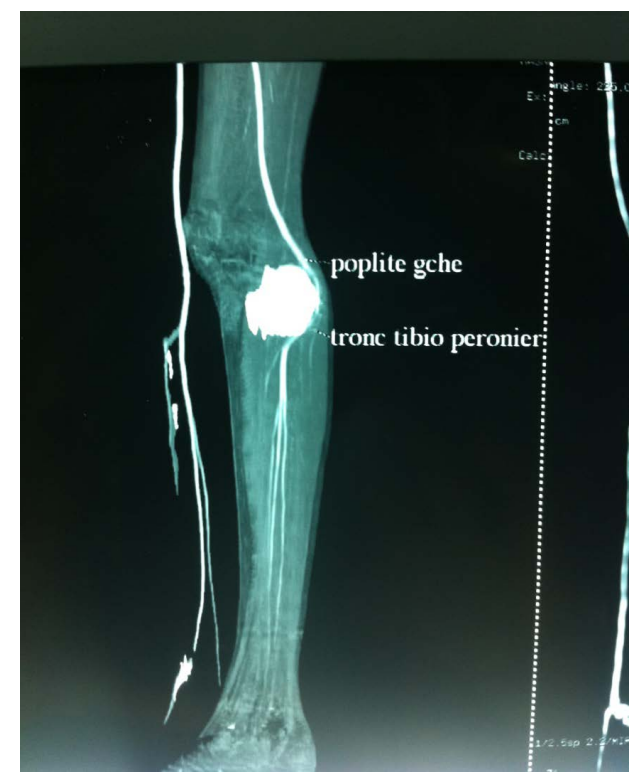

Figure 3. MRI angiography showed osteochondroma driving back significantly the popliteal neurovascular bundle posteriorly with a risk of intimal injury,

like cited by Hemli and Horaky [7] [9]. the dangerous location and the volume of the mass, the intimate contact with the pedicle objectified by further examination, make the surgical excision imperative to prevent a significant nerve or vascular complication in this case, also several case studies report the vascular complications of exostosis serving a metaphyseal especially knee [3] [4] [6]-[9]. Also, pain, limitation of flexion and gradual increase pushed us to surgical cure, since in terms of exostosis, the rule is: any painful exostosis must be removed because the risks of degeneration are real but rare [5]. 


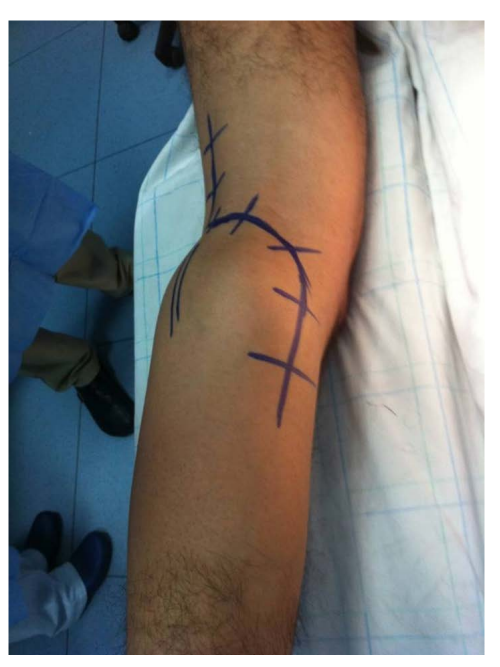

Figure 4. The excision of the entire lesion using a Triquet surgical exposure

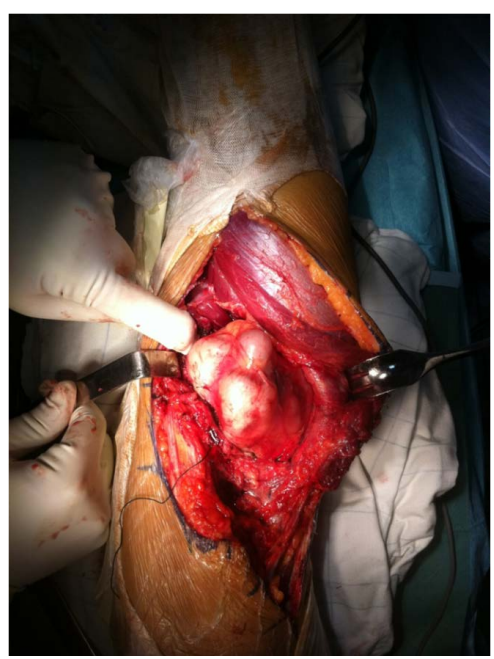

Figure 5. The sparing of the neurovascular bundle that has an intimate relationship with the mass.

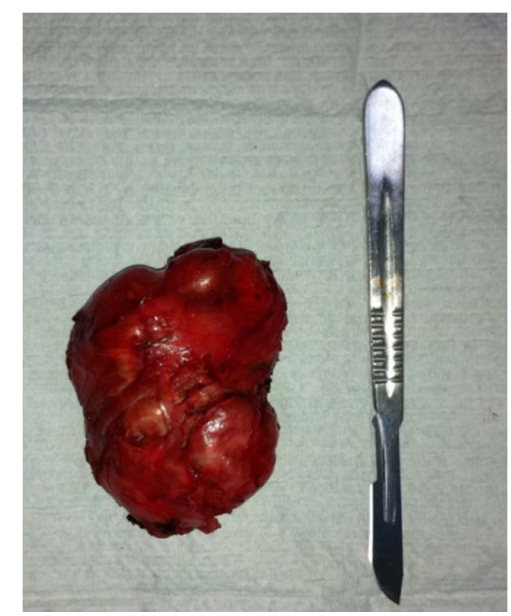

Figure 6. The volume of the osteochondroma masse. 
Like in our case, To confirm the diagnosis and assess risk, MRI angiography and CT angiography are necessary to clarify the relationship between exostosis and arterial axis in the preoperative surgical planning [6], and we have not omitted the significant risk of vascular lesion preoperatively, indeed the cartilaginous exostosis layer is thinned with age and becomes rougher, she is responsible for irritation and strain of mobile vascular walls to contact the lesion, which can break afterwards [3].

Faced with clinical and radiological arguments that demonstrate the conflict between exostosis and popliteal vascular axis, it seems logical to indicate surgical resection in this case.

\section{Conclusion}

The presence of an exostosis on an arterial route is a permanent danger that may cause vascular compression or pseudoaneurysma [4] [6] [7], this risk will always be confirmed by clinical and radiological data necessary to put the surgical indication to prevent these vascular complications [4] [6].

\section{References}

[1] Gouin, F., Venet, G. and Moreau, A. (2001) Solitary Exostosis, Exostosante Disease and Other Exostosis. Encycl Méd Chir, Appareil locomoteur, 14-724, 9 p.

[2] Wirganowicz, P/Z. and Watts, H.G. (1997) Surgical Risk for Elective Excision of Benign Exostoses. Journal of Pediatric Orthopaedics, 17, 455-459.

[3] Asselineau, A., Cobret, P. and Lahoud, J.C. (1993) Pseudoaneurysm of the Femoral Artery Complicating Exostosis. Revue De Chirurgie Orthopedique, 79, 411-414.

[4] Cassie, G.F., Dawson, A.S. and Sheville, E. (1975) False Aneurysm of the Femoral Artery from Cancellous Exostosis of Femur. The Journal of Bone \& Joint Surgery, 57B, 379.

[5] Erler, K., Ozdemir, M.T., Oguz, E. and Bazbozkurt, M. (2004) Does False Aneurysm Behave Like a Sarcoma? Distal Femoral Arterial False Aneurysm Simulated a Malign Mesenchymal Tumor. Archives of Orthopaedic and Trauma Surgery, 124, 60-63. http://dx.doi.org/10.1007/s00402-003-0595-8

[6] Greenway, G., Resnick, D. and Bookstein, J.J. (1979) Popliteal Pseudoaneurysm as a Complication of an Adjacent Osteochondroma: Angiographic Diagnosis. American Journal of Roentgenology, 132, 294-296. http://dx.doi.org/10.2214/ajr.132.2.294

[7] Hemli, J.M., Barakate, M.S., Puttaswamy, V. and Amppleberg, M. (2000) Popliteal Artery Compression by a Tibial Osteochondroma with Associated Thrombosis and Distal Embolisation. ANZ Journal of Surgery, 70, 459-461. http://dx.doi.org/10.1046/j.1440-1622.2000.01848.x

[8] Horaky, E., Benko, K., Mandi, B. and Mizsak, L. (2003) Femur osteochondroma okozta artéria poplitea pseudoaneurysma és vénapoplitea thrombosis. Osteologiai Kozlemenyek, 1, 31-33.

[9] Kieffer, E., Maraval, M., Trico, J.F. and Natali, J. (1978) Arterial Aneurysm Complicating Osteogenic Exostosis of the Upper End of the Tibia. Revue De Chirurgie Orthopedique, 64, 155-162. 
Submit or recommend next manuscript to OALib Journal and we will provide best service for you:

- Publication frequency: Monthly

- 9 subject areas of science, technology and medicine

- Fair and rigorous peer-review system

- Fast publication process

- Article promotion in various social networking sites (LinkedIn, Facebook, Twitter, etc.)

- Maximum dissemination of your research work

Submit Your Paper Online: Click Here to Submit

Contact Us: service@oalib.com 